\title{
Comentario Penélope Dransart ${ }^{1}$
}

El ensayo sobre la casa enquelgueña por Václav Šolc forma parte de un cuerpo de estudios que investigan la forma de la casa andina dentro de un contexto social y cultural. Denise Arnold (1992:34, Nota 2) ha presentado detalles sobre la bibliografía de estudios escritos por autores que han examinado la casa en el mundo andino. Además dice que Duncan Earle (1986) comparó el simbolismo de la casa quiché con el de la casa aymara.

En su trabajo, Arnold (1992: Figura 6) ha colocado la casa en la categoría de cosmos: "las casas como cosmos y cosmogonía”. En Qaqachaka, Bolivia, los moradores observan diversas prácticas en la construcción de sus casas que, según Arnold (1992:36), constituyen un "arte de la memoria" vinculado con el parentesco. La casa y sus descendientes producen la multiplicación de las casas en los sectores familiares observados por Šolc. Sin embargo, el conjunto de las casas que pertenecen a una familia nuclear en Enquelga no se asemeja a la agrupación alrededor de un patio que se nota en Qaqachaka (Arnold 1992: Figura 2). Los grupos familiares de casas en Enquelga no están cercados y este agrupamiento hasta la década de 1990 facilitó la tarea de vigilar los rebaños de camélidos y ovejas.

En Enquelga las mujeres, como los varones, heredan unas casas de sus padres. Hoy en día el padrón de dueños y dueñas es más disperso que el que predominaba en la época de 1968-69. Hay una proliferación de casas. No obstante, con una migración notoria de la gente a otros lugares (por ejemplo a Pozo Almonte, Iquique, Arica y hasta Cochabamba en Bolivia), hay cierta concentración, por lo cual los miembros de una familia escogen unas casas para vivir mientras algunas otras están cayéndose en desuso.

La iglesia de Enquelga alberga tres pequeñas imágenes de San Antonio de Padua, que corresponden a los tres apellidos de la estancia: las familias Condori y Mamani y las dos familias Castro (Dransart 2002:56). San Antonio, patrón de los animales de rebaño, simboliza la importancia del pastoreo en la economía islugueña. Šolc explica que, en 1968-69, las casas más antiguas de Enquelga se remontaban solamente a los 120 años de edad. Según él, las "autoridades blancas" obligaron a los islugueños de juntarse en poblaciones concentradas. Se trata de otra reducción; Gabriel Martínez (1976) examinó el plan del pueblo ceremonial de Islug Marka como producto de la reducción que se realizó durante la época colonial. Estas imposiciones han enfatizado la patrilocalidad que aparentemente caracteriza las comunidades de la zona. No obstante, una señora originaria de otra estancia en Isluga nunca pierde el derecho de pastorear sus llamas, alpacas u ovejas, y también las de su marido y sus niños, en los bofedales de su comunidad de origen (Dransart 1996:33). Los miembros de una familia poseen una red de casas en varios lugares. El bofedal compartido por los lugareños de Enquelga, Ch'api Qullu y Karawanu, es pequeño. Entonces la gente tiene que mantener un ciclo de trashumancia horizontal durante el año y las familias tienen residencias en varios lugares en Isluga.

Mucha gente en Enquelga tiene una casa en Jalsuri, donde un ojo doble de agua riega pasto de buena calidad. El agua fluye hasta el pueblo, Islug Marka, donde se junta con el río principal. En Jalsuri hay un agrupamiento de casas pertenecientes a algunas familias de la mitad de abajo -este grupo se llama Choque Jalsuri- mientras las casas de la gente de Enquelga (que pertenece a la mitad de arriba) se llaman Castro Jalsuri. Estas últimas casas están más aisladas y no se conforman a un grupo. Jalsuri todavía corresponde a la descripción presentada por Šolc de Enquelga hace 30 o 40 años.

Entre la época de 1968-69 y la época de mi primera estadía en Enquelga en 1986, se cambió el alineamiento del camino. En el plan de Šolc, éste corría al sur de la iglesia y al sur de las casas de Isidro Castro y la casa número 71 de Julio Castro. Ahora el camino sigue el lado norte de la iglesia y de estas dichas casas. El 9 de febrero de 1987 participé en la ceremonia del techado de una nueva casa destinada a dos de las hijas de Isidro Castro y la difunta Gabriela Mamani Challapa. Se sacrificó un cordero para rociar su sangre sobre las paredes. Esta casa está situada con el eje en línea perpendicular a las casas de Isidro Castro en el plan, y tiene la puerta hacia el norte, hacia el cerro volcán

School of Archaeology, History and Anthropology, University of Wales Trinity St David, Wales, UK. p.dransart@tsd.ac.uk 
de Isluga. Entonces la familia tiene un conjunto de casas alrededor de un espacio de un carácter más cercado que antes.

En el simbolismo de la casa en Qaqachaka, hay una analogía entre la casa y un nido de envolturas tejidas (Arnold 1992:55). Aquí quiero mencionar la casa en Enquelga como despensa de productos textiles. Como dice Šolc, en la casa hay una falta de muebles. Estacas de madera fijadas en las paredes llevan sogas trenzadas, producto de la labor masculina. Una soga tendida de una estaca empotrada en una pared larga a otra en la pared opuesta sostiene ropa como, por ejemplo, urk" $u$ (traje femenino), awayu (manta) y poncho (una prenda masculina). Toda esta ropa es producto de la labor femenina. La cantidad de sogas y de tejidos señala el éxito de la familia en el cuidado de sus camélidos. Si el rebaño se aumenta, los dueños tienen mucho vellón para tejer y trenzar.

Šolc menciona la ausencia de ventanas en la mayoría de las casas. Hoy en día las casas tienden a ser más grandes, construidas de adobe y, además, de madera, cemento, calamina y vidrio importados. Sin embargo, el interior de la casa queda relativamente oscuro. La casa de Catalina (otra casa más nueva que el plan de Šolc) donde dormí sobre una plataforma en los años de la década 1980 era muy oscura adentro. Adentro tenía dos zarcillos hechos de hilos de color vivo, una mazorquita de maíz y una botellita de aguardiente pendientes de las vigas del techo.

Simbólicamente, Eva Hunt (1977:133-4) observa que existe una analogía entre el interior de una cueva y el de una casa entre los zinacantecos de México. También menciona que no hay ventanas en las casas zinacantecas (Hunt 1977:176). Vale la pena examinar esta oscuridad interior dado que anteriormente las tejedoras de Isluga no utilizaban muchos colores teñidos en sus textiles, y los zarcillos se caracterizan por su color intenso. Verónica Cereceda (1987:189) describe una conformación textil de listas angostas llamada $k$ 'isa como un "destello brillante, luminoso". No obstante, las tejedoras tejen frazadas caracterizadas por el uso de color vivo -el diseño consiste en $k$ 'isa seguido de inmediato por $k^{\prime} i s a$, casi sin ruptura alguna. En otros tejidos (el poncho masculino y el traje femenino que se llama $u r k$ " $u$ ), hay extensiones de colores naturales, o sea colores sobrios. Para Cereceda las frazadas enteramente "k'isadas" son peligrosas -en Isluga se teme a los colores fuertes y brillantes asociados con los minerales adentro de la tierra. En su opinión, la falta de articular la sucesión de k’isa en la frazada representa la asocialidad: "La continuidad sin ruptura es percibida como peligrosa (no articulación = asocialidad)" (Cereceda 1987:193).

Entonces surge una pregunta: ¿por qué tejen las mujeres estas frazadas con tanto color vivo para proteger a los miembros de su familia? La paradoja desaparece si tomamos en cuenta el contexto de utilizar las frazadas. En la oscuridad, como adentro de una cueva, o adentro de la casa, y durante la noche, los colores vivos “se apaguen”. De ahí surge la importancia de combinar colores intensos en las frazadas. En la luz del día las tejedoras de Enquelga favorecen un contraste entre el color no teñido del vellón de las llamas o alpacas y el uso más restringido de colores vivos (Dransart 1988:47). La intensidad de color es necesaria en una frazada, destinada por uso adentro de la oscuridad de la casa.

Ahora hay una calle principal en Enquelga, la escuela engrandecida se ubica en la plaza central, hay una iglesia pentecostal, un sistema de luz (que no siempre funciona) y agua potable, etcétera. Hay muchos cambios. No obstante, el ciclo del año y el cuidado de camélidos continúa. En forma de conclusión, quisiera dar mi más sincera gratitud a toda la gente de Enquelga por su cariño, especialmente a Tata Marcos Castro y a la difunta Mama Natividad Castro Challapa y su familia.

\section{Referencias Citadas}

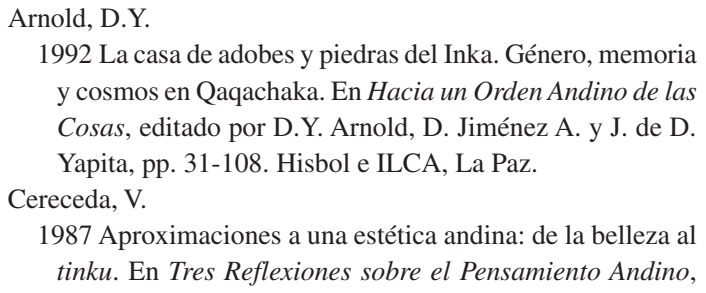

editado por T. Bousse-Cassagne, O. Harris, T. Platt y V. Cereceda, pp. 133-226. Hisbol, La Paz.

Dransart, $\mathrm{P}$.

1988 Continuidad y cambio en la producción textil tradicional aymara. Hombre y Desierto. Una Perspectiva Cultural 2:41-57.

1996 Las flores de los rebaños en Isluga. La vida cultural de los ganaderos y camélidos en el Norte de Chile. Nuevo Texto Crítico 9(18):29-39. 
2002 Earth, Fleece and Fabric: An Ethnography and Archaeology of Andean Camelid Herding. Routledge, London. Earle, D.M.

1986 The metaphor of the day in Quiché: notes on the nature of everyday life. En Symbol and Meaning Beyond the Closed Community: Essays in Mesoamerican Ideas, editado por G.H. Gossen, pp. 155-172. University of Texas Press, Austin.
Hunt, E.

1977 The Transformation of the Hummingbird: Cultural Roots of a Zinacantecan Mythical Poem. Cornell University Press, Ithaca y Londres.

Martínez, G.

1976 El sistema de los uywiris en Isluga. Anales de la Universidad del Norte (Homenaje al Dr Gustavo Le Paige S.J.) 10:255-327. 